\title{
PENERAPAN ETIKET BISNIS PERUSAHAAN JEPANG DI INDONESIA OLEH PEKERJA LOKAL
}

\section{IMPLEMENTATION OF JAPANESE COMPANIES BUSINESS ETIQUETTE IN INDONESIA BY LOCAL EMPLOYEES}

\section{Fadhila Arienda Humaira}

Universitas Suryakancana, Jl. Pasirgede Raya, Bojongherang, Cianjur 43216

Email : Fadhilaarienda@gmail.com

\begin{tabular}{|l|l|l}
\hline Masuk: 14 Juni 2021 & Penerimaan: 15 Juni 2021 & Publikasi: 28 Juni 2021
\end{tabular}

\begin{abstract}
ABSTRAK
Perusahaan-perusahaan Jepang yang berdiri di luar Jepang khususnya di Indonesia menerapkan nilai-nilai budaya negaranya termasuk etiket berbisnis. Penelitian ini bertujuan untuk mendeskripsikan penerapan etiket bisnis pekerja lokal yang bekerja di perusahaan Jepang di Indonesia. Metode yang digunakan dengan pendekatan kualitatif yaitu dengan studi kepustakaan dan pembagian kuesioner kemudian dianalisis dengan metode deskriptif. Hasil penelitian menunjukkaan bahwa penerapan etiket bisnis ala Jepang pekerja lokal di perusahaan Jepang memiliki intensitas yang berbeda-beda tergantung dari jenis pekerjaan yang dilakukan. Dalam hal aisatsu (salam), dan menelepon dengan etiket bisnis Jepang memiliki intensitas penerapan tinggi. Namun, intensitas penerapan rendah dalam hal bertukar kartu nama dengan ekspatriat Jepang. Kemudian, ojigi (membungkuk) diterapkan oleh pekerja lokal ketika bertemu, meminta maaf, berterimakasih, dan meminta tolong kepada ekspatriat Jepang.
\end{abstract}

Kata kunci: Penerapan, Etiket, Bisnis, Jepang, Pekerja

\section{ABSTRACT}

Japanese companies that are established outside of Japan, especially in Indonesia, implementing cultural values of their country, including business etiquette. This study aims to describe the implementation of business etiquette for local employee who work in Japanese companies in Indonesia. The method used a qualitative approach is literature studies and distribution of questionnaires then analyzed by descriptive method. The results showed that the implementation of Japanese-style business etiquette for local employee in Japanese companies bad different intensities depending on the occupation. In the case of aisatsu (greeting), and calling with Japanese business etiquette has a high implementation intensity. However, the intensity is low exchanging business cards with Japanese expatriate. Then, ojigi (bowing) is applied by local employee when meeting, apologizing, thanking, and asking Japanese expatriate for help.

Keywords: Implementation, Etiquette, Business, Japanese, Employee

\section{PENDAHULUAN}

Jepang merupakan negara dengan kemajuan teknologi, bisnis yang sangat pesat. Berkembangnya banyak sektor bisnis dapat dilihat dari berdirinya perusahaan-perusahaan Jepang di penjuru dunia, termasuk Indonesia. Mantan Duta Besar Jepang untuk Indonesia, Masafumi Ishi menyatakan Jepang salah satu mitra bisnis Indonesia terbesar, di antaranya melalui 1.500 perusahaan Jepang yang beroperasi di Indonesia. Perusahaan Jepang di Indonesia menyerap 4,7 juta tenaga kerja, dan sekitar 93,3\% tenaga kerja di perusahaan Jepang di Indonesia adalah pekerja lokal. 
Berdasarkan survei Japan External Trade Organization (JETRO) mengenai "Kondisi Bisnis Perusahaan Jepang di Asia dan Oseania Tahun 2019” yang dijelaskan pula mengenai kondisi perusahaan Jepang di Indonesia, keuntungan dalam iklim di Indonesia tertinggi kedua setelah India (90.7\%) dengan skala pertumbuhan pasar mencapai 83.4\%. Ditambah dengan persentase pendapatan perusahaan yang untung di tahun 2019 sebanyak 69.1\%, yang terus mengalami kenaikan dari tahun sebelumnya. Potensi pertumbuhan pasar Indonesia yang mencapai 58,4\% merupakan yang tertinggi dari seluruh negara responden survei (Jetro, 2020 : 3).

Perusahaan-perusahaan Jepang yang berdiri di luar Jepang pun kerap menerapkan pula nilai-nilai budaya negaranya termasuk dalam kehidupan berbisnis. Salah satu implementasi dari nilai budaya yang diterapkan adalah etiket bisnis Jepang.

Chang (2016 : 95) menjelaskan etiket berasal dari kata etiquette (Prancis), yang tak terlepas dari kata dasar ethos (Yunani). Etiket berarti seperangkat kebiasaan dan aturan untuk perilaku yang sopan, khususnya di antara kalangan masyarakat kelas tertentu atau di kalangan profesi tertentu. Etiket biasanya terkait dengan tata krama atau sopan santun dalam hidup manusia sehari-hari.

Tamura (2013 : 2) secara spesifik menjelaskan bahwa etiket bisnis adalah sikap sopan santun sebagai anggota masyarakat yang diperlukan saat berkomunikasi dengan rekan kerja, senior, atasan, dan klien perusahaan. Dalam masyarakat bisnis, orang-orang yang terlibat datang dari berbagai latar belakang usia, jenis kelamin, posisi, cara berpikir dan lainnya. Adanya etiket bisnis dapat menjadi jembatan untuk membangun hubungan kepercayaan dan dengan lancar melampau perbedaan-perbedaan yang ada.

Berbagai negara secara umum memiliki tata krama yang hampir sama, namun ada pula beberapa perbedaan disesuaikan dengan budaya yang dianut. Seperti dalam budaya masyarakat Jepang, Aisatsu (Salam) dan Ojigi (membungkuk) menjadi etiket yang tidak terhindarkan dalam kehidupan sehari-hari di lingkungan publik. Etiket publik ini menjadi dasar dari etiket bisnis. Ditambah lagi dengan etiket bertukar kartu nama atau yang disebut Meishi Koukan. Menjadi hal yang diperhatikan dari mulai sikap dan tata caranya.

Dalam Kojien Dictionary (2012 : 23) Aisatsu adalah 人に会ったり別れたりするとき

\section{、礼儀的にとり交わす言葉や動作。Hito ni attari wakare tari suru toki, reigi-teki ni tori kawasu}

kotoba ya dousa. Artinya : Pertukaran kata-kata dan tindakan dengan sopan ketika bertemu dan berpisah dengan orang. 
Dalam Bahasa Indonesia diartikan sebagai salam. Dalam kehidupan masyarakat Jepang, tata krama salam memiliki peran penting dalam menghubungkan hati dan memulai percakapan dengan lancar. Saat memberi salam, ada beberapa hal yang harus diperhatikan :

1. Mengucapkan salam mulai dari diri sendiri;

2. Suara lantang dan ceria agar terdengar oleh orang lain;

3. Menatap lawan bicara;

4. Memberikan kesan yang tulus dengan senyum yang alami;

5. Memberi salam dengan menyesuaikan posisi lawan bicara (atasan, teman, klien).

Menurut Koga (dalam Shibata, 2015 : 571) Ojigi adalah お辞儀には立礼と座礼があり，

\section{どちらも上体を屈する角度による分類がある。Ojigi niwa ritsurei to zairei ga ari, dochiramo}

joutai o kussuru katsudou ni yoru bunrui ga aru. Artinya : Ada dua jenis ojigi yaitu sambil berdiri dan duduk, keduanya diklasifikasikan menurut derajat dimana tubuh bagian atas membungkuk. Klasifikasi tersebut dirangkum Koga (dalam Shibata 2015: 571), misalnya jenis membungkuk sambil berdiri dibagi kedalam empat klasifikasi yaitu Eshaku (15 derajat), Keirei (30 derajat), Saikeirei (45 derajat), dan Hairei (90 derajat). Eshaku merupakan anggukan paling ringan, keirei anggukan yang biasanya digunakan (30 derajat) dan hairei merupakan anggukan paling hormat (sekitar 90 derajat) yang digunakan untuk menyembah dewa Buddha.

Di dunia bisnis, kartu nama menjadi tahap awal untuk mengenali diri. Ketika bertemu dengan orang, dimulai dari bertukar kartu nama. Melalui kartu nama dapat memicu percakapan lebih lanjut. Adapun yang etiket bertukar kartu nama yang diperhatikan oleh orang Jepang adalah, menerima kartu nama dengan kedua tangan sambil sedikit membungkukkan badan, setelah bertukar kartu nama dan memulai pertemuan mengingat wajah dan nama lawan bicara, meletakkan kartu nama di atas meja dan membariskankan sesuai posisi duduk tamu/klien.

Telepon sebagai alat komunikasi yang mudah dan praktis. Dapat digunakan oleh siapa saja, dan sangat diperlukan dalam kegiatan berbisnis. Oleh karena itu, dalam berkomunikasi menggunakan telepon, terdapat etiket yang biasa diterapkan dalam kegiatan bisnis. Dalam Tamura (2013 : 47) ada empat poin dalam etiket menelepon, yaitu :

1. Benar (Berkomunikasi dan mendengarkan dengan seksama, berhati-hati dengan kesalahpahaman);

2. Cepat (Segera mengangkat telepon, tidak membuat lawan bicara menunggu);

3. Ringkas (Tidak bertele-tele, menyampaikan to the point) ; 
4. Sopan (Perhatikan kata-kata, gaya bicara \& selalu mengingat dan bertindak sebagai perwakilan perusahaan).

Etiket bisnis diatas, merupakan etiket yang turut diterapkan dalam kehidupan berbisnis perusahaan Jepang yang ada di Indonesia. Oleh karena itu, dalam penelitian ini selain bertujuan untuk mendeskripsikan etiket bisnis yang dianut oleh orang Jepang, juga bertujuan untuk mengetahui bagaimanakah penerapannya oleh para pekerja lokal yang bekerja di perusahaan Jepang yang ada di Indonesia. Hal ini membuka wawasan dan pemahaman kepada orang-orang yang akan dan atau telah bekerja di perusahaan Jepang, agar dapat mudah beradaptasi dengan prinsip-prinsip yang dijunjung dalam budaya bekerja dan bisnis orang Jepang.

\section{METODE PENELITIAN}

Metode penelitian yang digunakan adalah penelitian deskriptif dengan pendekatan kualitatif yaitu dengan studi kepustakaan dan pembagian kuesioner sebagai teknik pengumpulan datanya. Sampel penelitian adalah para pekerja lokal Indonesia yang bekerja di perusahaan Jepang sebanyak sepuluh responden. Jenis kuesioner yang dibagikan merupakan kuesioner campuran, yang dibagi menjadi tiga bagian. Pada bagian pertama mendata bidang perusahaan, jabatan responden dalam pekerjaan. Bagian kedua, kuesioner berjenjang yang berisi pertanyaan mengenai intensitas penerapan etiket bisnis Jepang oleh responden. Etiket bisnis yang menjadi objek penelitian dibatasi hanya empat jenis etiket yang paling mencerminkan budaya bisnis Jepang yaitu Aisatsu (salam), Ojigi (membungkuk), Meishi Konkan (Bertukar kartu nama, dan Denwa manaa (Etiket menelepon). Dan dibagian ketiga, merupakan pertanyaan terbuka dimana responden dapat menjawab secara bebas mengenai alasan pentingnya penerapan etiket bisnis Jepang dan pendapat mengenai hal yang harus diperhatikan saat akan bekerja di perusahaan Jepang.

Data yang diperoleh dalam penelitian ini didapat dari sepuluh responden yang bekerja di perusahaan Jepang yang bergerak dalam bidang manufaktur, otomotif, perekrutan tenaga kerja, trading, pendidikan, telekomunikasi, dan logistik.

\section{HASIL DAN PEMBAHASAN}

Data yang terkumpul melalui kuesioner dengan sampel sepuluh orang responden merupakan pekerja lokal yang bekerja di perusahaan Jepang di Indonesia. Adapun bidang perusahaan Jepang responden dapat dilihat dalam tabel berikut. 
Tabel 1. Bidang Perusahaan Responden

\begin{tabular}{ll}
\hline \multicolumn{1}{c}{ Bidang Perusahaan } & Jumlah orang \\
\hline Manufaktur & 2 \\
\hline Otomotif & 1 \\
\hline Perekrutan & 2 \\
\hline Trading & 1 \\
\hline Pendidikan & 2 \\
\hline Telekomunikasi & 1 \\
\hline Logistik & 1 \\
\hline
\end{tabular}

Bidang perusahaan responden diatas belum dapat dikatakan mewakili seluruh bidang perusahaan Jepang yang ada di Indonesia, tetapi tujuh bidang perusahaan tersebut dapat memberikan gambaran secara umum mengenai jenis-jenis bisnis perusahaan Jepang yang berkembang di Indonesia.

Tabel 2. Jabatan Responden di Perusahaan

\begin{tabular}{lc}
\hline \multicolumn{1}{c}{ Jabatan di Perusahaan } & Jumlah orang \\
\hline Staf Administrasi & 1 \\
\hline Staf Marketing & 3 \\
\hline Engineer & 1 \\
\hline Pengajar & 2 \\
\hline Penerjemah & 1 \\
\hline Sekretaris & 1 \\
\hline Staf penelitian \& & 2 \\
pengembangan $(R \odot D)$ & \\
\hline
\end{tabular}

Tabel 3. Intensitas Penerapan Etiket Aisatsu Responden

\begin{tabular}{lccccc}
\hline A. Etiket Aisatsu & Selalu & Sering & $\begin{array}{c}\text { Kadang- } \\
\text { kadang }\end{array}$ & Jarang & $\begin{array}{c}\text { Tidak } \\
\text { pernah }\end{array}$ \\
\hline $\begin{array}{l}\text { 1. } \begin{array}{l}\text { Mengucapkan salam } \\
\text { menggunakan Bahasa }\end{array} \\
\begin{array}{l}\text { Jepang kepada } \\
\text { atasan/rekan/tamu } \\
\text { ekspatriat Jepang }\end{array}\end{array}$ & 6 & 1 & - & 1 & 2 \\
\hline $\begin{array}{l}\text { Mengucapkan salam } \\
\text { dengan senyuman }\end{array}$ & 7 & 2 & 1 & - & - \\
\hline 3. $\begin{array}{l}\text { Memberi salam lebih } \\
\text { dulu daripada orang lain }\end{array}$ & 2 & 7 & 1 & - & - \\
\hline 4. $\begin{array}{l}\text { Mengucapkan salam } \\
\text { dengan suara lantang } \\
\text { agar terdengar oleh } \\
\text { orang lain }\end{array}$ & 2 & 1 & 3 & 4 & - \\
\hline $\begin{array}{l}\text { Mengucapkan salam saat } \\
\text { bertemu orang-orang di } \\
\text { kantor }\end{array}$ & 6 & 2 & 1 & 1 & - \\
\hline 6. $\begin{array}{l}\text { Mengucapkan salam } \\
\text { perpisahan kepada } \\
\text { orang-orang di kantor }\end{array}$ & 8 & 2 & - & - & - \\
\hline
\end{tabular}


Dilihat dari tabel jabatan responden diatas, dapat memberikan gambaran secara umum mengenai jenis-jenis pekerjaan pekerja lokal di perusahaan Jepang di Indonesia. Hal ini pun dapat menjadi petunjuk mengenai bagaimana etiket bisnis yang diterapkan sesuai dengan jabatan yang dipegang oleh responden.

Hasil dari kuesioner bagian dua berupa angka yang menunjukkan jumlah responden yang menerapkan etiket bisnis Jepang berdasarkan intensitasnya (selalu, sering, kadang-kadang, jarang, dan tidak pernah). Adapun intensitas berbagai etiket bisnis dalam aisatsu (salam) adalah sebagai berikut.

Berdasarkan Tabel 3 di atas, lebih dari setengah responden memilih jawaban selalu dan sering dalam intensitas penerapan etiket pengucapan salam, hal ini dilihat dalam kegiatan mengucapkan salam dengan tersenyum (A.2), memberi salam lebih dalulu daripada orang lain (A.3), mengucapkan salam saat bertemu orang-orang di kantor (A.5), dan saat pulang lebih awal mengucapkan salam perpisahan kepada orang-orang di kantor (A.6). Ini menunjukkan bahwa aisatsu (salam) sebagai sebuah etiket bisnis sudah biasa digunakan oleh orang Indonesia di lingkungan pekerjaan. Kemudian, dalam berinteraksi dengan ekspatriat Jepang, mayoritas pekerja lokal menggunakan salam dalam bahasa Jepang.

Tabel 4. Intensitas Penerapan Etiket Ojigi Responden

\begin{tabular}{|c|c|c|c|c|c|}
\hline B. Etiket Ojigi & Selalu & Sering & $\begin{array}{l}\text { Kadang- } \\
\text { kadang }\end{array}$ & Jarang & Tidak pernah \\
\hline $\begin{array}{l}\text { 1. Melakukan ojigi saat } \\
\text { memberi/menjawab salam } \\
\text { atasan/rekan/tamu } \\
\text { ekspatriat Jepang }\end{array}$ & 4 & 1 & 3 & - & 2 \\
\hline $\begin{array}{l}\text { 2. Melakukan ojigi saat } \\
\text { bertemu dengan } \\
\text { klien/tamu ekspatriat } \\
\text { Jepang }\end{array}$ & 6 & 1 & 1 & - & 2 \\
\hline $\begin{array}{l}\text { 3. Melakukan ojigi saat } \\
\text { meminta bantuan secara } \\
\text { langsung kepada } \\
\text { atasan/rekan/tamu } \\
\text { ekspatriat Jepang } \\
\end{array}$ & 3 & 3 & 2 & - & 2 \\
\hline $\begin{array}{l}\text { 4. Melakukan ojigi saat } \\
\text { berterimakasih secara } \\
\text { langsung kepada } \\
\text { atasan/rekan/tamu } \\
\text { ekspatriat Jepang }\end{array}$ & 4 & 3 & 2 & - & 1 \\
\hline $\begin{array}{l}\text { 5. Melakukan ojigi saat } \\
\text { meminta maaf secara } \\
\text { langsung kepada } \\
\text { atasan/rekan/tamu } \\
\text { ekspatriat Jepang }\end{array}$ & 4 & 3 & 2 & - & 1 \\
\hline $\begin{array}{l}\text { 6. Melakukan kontak mata } \\
\text { kepada lawan bicara } \\
\text { sebelum dan sesudah ojigi }\end{array}$ & 1 & 4 & 3 & 1 & 1 \\
\hline
\end{tabular}


Selanjutnya, berdasarkan Tabel 4, ketika berinteraksi khususnya saat bertemu, meminta maaf, berterimakasih, dan meminta tolong kepada ekspatriat Jepang, pekerja lokal cenderung melakukan ojigi (membungkuk) walaupun dalam budaya Indonesia tidak menerapkan sikap membungkuk seperti yang biasa dilakukan oleh orang Jepang dalam etiket berbisnis. Hal ini menunjukkan, pekerja lokal menghormati lawan bicaranya, khususnya ekspatriat Jepang dengan menerapkan etiket bisnis Jepang. Namun, setengah responden belum tepat dalam menerapkan etiket ojigi sebagaimana yang diterapkan oleh orang Jepang yaitu, dengan menatap lawan bicara sebelum dan sesudah ojigi (B.6)

Tabel 5. Intensitas Penerapan Etiket Meishi Koukan Responden

\begin{tabular}{|c|c|c|c|c|c|}
\hline C. Etiket Meishi Koukan & Selalu & Sering & $\begin{array}{c}\text { Kadang- } \\
\text { kadang }\end{array}$ & Jarang & Tidak pernah \\
\hline $\begin{array}{l}\text { 1. Bertukar kartu nama dengan } \\
\text { ekspatriat Jepang }\end{array}$ & 2 & 1 & 3 & - & 4 \\
\hline $\begin{array}{l}\text { 2. Lebih dahulu mengeluarkan } \\
\text { kartu nama saat bertamu ke } \\
\text { perusahaan Jepang lain } \\
\text { untuk pertama kali }\end{array}$ & - & 3 & 3 & - & 4 \\
\hline $\begin{array}{l}\text { 3. Saat bertemu klien bersama } \\
\text { atasan, atasan lebih dulu } \\
\text { bertukar kartu nama dengan } \\
\text { tamu/klien }\end{array}$ & 4 & 1 & 2 & - & 3 \\
\hline $\begin{array}{l}\text { 4. Menggunakan kedua tangan } \\
\text { saat bertukar kartu nama }\end{array}$ & 5 & 2 & 1 & - & 2 \\
\hline $\begin{array}{l}\text { 5. Badan sedikit membungkuk } \\
\text { saat bertukar kartu nama }\end{array}$ & 4 & 4 & - & - & 2 \\
\hline $\begin{array}{l}\text { 6. Menyerahkan kartu nama } \\
\text { dengan posisi huruf } \\
\text { menghadap lawan bicara }\end{array}$ & 4 & 4 & - & - & 2 \\
\hline $\begin{array}{l}\text { 7. Meletakkan kartu nama yang } \\
\text { baru saja diterima di atas } \\
\text { meja }\end{array}$ & 2 & 2 & 2 & - & 4 \\
\hline $\begin{array}{l}\text { 8. Saat tamu lebih dari satu, } \\
\text { menjajarkan kartu nama } \\
\text { sesuai urutan tempat duduk } \\
\text { klien/tamu }\end{array}$ & 2 & 3 & - & - & 5 \\
\hline $\begin{array}{l}\text { 9. Menanyakan beberapa } \\
\text { pertanyaan ringan seputar } \\
\text { hal yang tertera di kartu } \\
\text { nama }\end{array}$ & - & 1 & 2 & 2 & 5 \\
\hline $\begin{array}{l}\text { 10. Setelah pertemuan selesai, } \\
\text { menyimpan kartu nama di } \\
\text { wadah/ kotak kartu }\end{array}$ & 4 & 4 & - & - & 2 \\
\hline
\end{tabular}

Kemudian, intensitas penerapan etiket meishi koukan (bertukar kartu nama) oleh responden (Tabel 5) menunjukan intensitas rendah dalam hal bertukar kartu nama dengan ekspatriat Jepang (C.1), hal ini dapat disebabkan oleh jenis pekerjaan yang dilakukan oleh responden di tempat kerja tidak selalu bersinggungan dengan ekspatriat Jepang. Namun dalam kegiatan bertukar kartu nama secara umum, mayoritas responden telah melakukan etiket 
tersebut dengan baik seperti menggunakan kedua tangan (C.4), badan sedikit membungkuk (C.5), menyerahkan kartu nama dengan posisi huruf menghadap lawan bicara ketika bertukar kartu nama (C.6), dan menyimpan kartu nama yang diterima di wadah/kotak kartu setelah pertemuan selesai (C.10). Dapat disimpulkan bahwa, responden telah menerapkan sikap yang baik bertukar kartu nama sebagaimana yang dilakukan orang Jepang, walaupun belum dapat diterapkan secara sempurna.

Tabel 6. Intensitas Penerapan Denwa Manaa Responden

\begin{tabular}{|c|c|c|c|c|c|}
\hline D. Denwa Manaa & Selalu & Sering & $\begin{array}{l}\text { Kadang- } \\
\text { kadang }\end{array}$ & Jarang & Tidak pernah \\
\hline $\begin{array}{l}\text { 1. Menaruh memo dan alat tulis di } \\
\text { dekat telepon }\end{array}$ & 7 & - & - & 2 & 1 \\
\hline $\begin{array}{l}\text { 2. Saat telepon berdering, } \\
\text { menghentikankan pekerjaan } \\
\text { untuk sementara dan segera } \\
\text { mengangkat telepon agar } \\
\text { penelepon tidak menunggu lama }\end{array}$ & 8 & 2 & - & - & - \\
\hline $\begin{array}{l}\text { 3. Saat menelepon } / \text { menerima } \\
\text { telepon, pertama kali } \\
\text { mengucapkan nama dan } \\
\text { perusahaan } \\
\end{array}$ & 7 & 1 & 2 & - & - \\
\hline $\begin{array}{l}\text { 4. Menanyakan/mengkonfirmasi } \\
\text { nama dan perusahaan lawan } \\
\text { bicara }\end{array}$ & 6 & 3 & 1 & - & - \\
\hline $\begin{array}{l}\text { 5. Menelepon/menerima telepon } \\
\text { dengan suara yang jelas, hangat } \\
\text { \& ceria }\end{array}$ & 3 & 6 & - & 1 & - \\
\hline $\begin{array}{l}\text { 6. Meminta maaf saat terlambat } \\
\text { mengangkat telepon }\end{array}$ & 2 & 2 & 4 & 1 & 1 \\
\hline $\begin{array}{l}\text { 7. Saat posisi Anda sebagai } \\
\text { penerima telepon, menutup } \\
\text { telepon setelah lawan bicara } \\
\text { mengakhiri panggilan }\end{array}$ & 5 & 4 & - & 1 & - \\
\hline
\end{tabular}

Kemudian etiket bisnis terakhir yang menjadi objek penelitian ini, adalah denwa manaa (etiket menelepon) menunjukkan hasil seperti di atas (Tabel 6). Dalam berbagai macam situasi yang menggambarkan etiket menelepon, intensitas penerapan sebagian besar responden tinggi. Hal ini mencerminkan, adanya persamaan etiket orang Indonesia dan orang Jepang dalam hal menelepon. Namun, lebih dari setengah responden cenderung jarang meminta maaf saat terlambat mengangkat telepon, selayaknya sikap yang dilakukan oleh orang Jepang. Ini terlihat dalam etiket (D.6). 


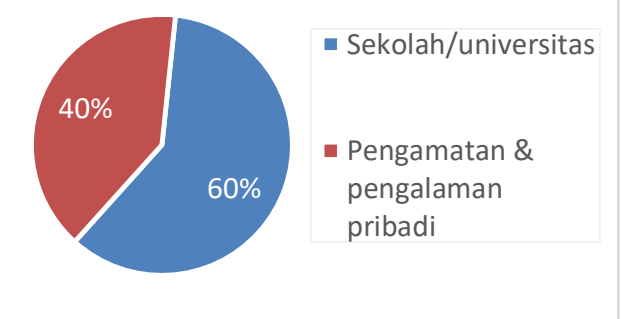

\section{Bagan 1. Sumber Pengetahuan Etiket Bisnis Responden}

Berdasarkan Bagan 1 di atas, 60\% responden mengetahui etiket bisnis Jepang melalui sekolah/universitas. Hal ini menunjukkan bahwa responden dengan latar belakang pendidikan bahasa atau sastra Jepang, mendapatkan pengetahuan budaya Jepang termasuk etiket bisnis ketika berada di sekolah/universitas. Sedangkan, 40\% responden mengetahui etiket bisnis Jepang dari pengamatan dan pengalaman pribadinya ketika bekerja di perusahaan Jepang.

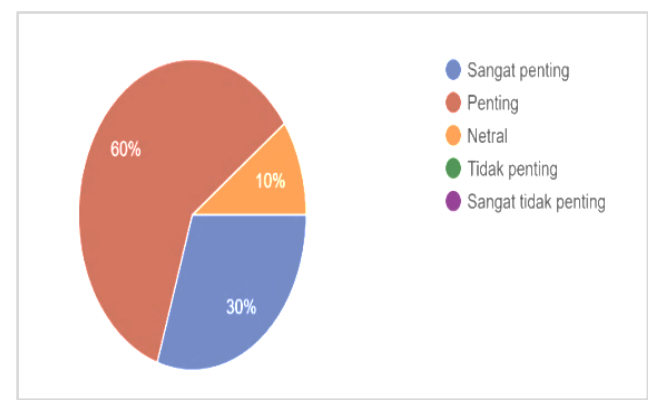

\section{Bagan 2, Pentingnya Penerapan Etiket Bisnis Jepang oleh Pegawai Lokal di Perusahaan Jepang di Indonesia}

Berdasarkan Bagan 2, responden diberikan pertanyaan mengenai pentingnya penerapan etiket bisnis perusahaan Jepang di Indonesia oleh pegawai lokal, 90\% responden berpendapat bahwa pegawai lokal penting untuk menerapkan etiket bisnis Jepang di kehidupan pekerjaannya. Alasan yang dikemukakan oleh mayoritas responden bahwa ketika bekerja di perusahaan Jepang, maka seluruh elemen perusahaan termasuk pegawai lokal harus mengikuti aturan dan budaya kerja perusahaan yang bersangkutan walaupun perusahaan tersebut berada di Indonesia. Hal ini untuk mengurangi kesalahpahaman akibat perbedaan budaya, dan sikap menghormati dan menjaga keharmonisan antar sesama, juga memperlancar kegiatan bisnis. Etiket bisnis kedua negara pun dapat dikombinasikan selama tidak melanggar nilai-nilai yang dianut oleh masing-masing negara.

Kemudian, dalam pertanyaan terakhir di kuesioner mengenai pendapat responden tentang hal apa saja yang harus diperhatikan oleh orang Indonesia yang akan bekerja di perusahaan Jepang, responden berpendapat bahwa kedisiplinan harus diperhatikan. Orang Jepang saat memperhatikan hal-hal kecil terutama mengenai waktu, maka pegawai lokal 
diharapkan selalu tepat waktu dalam berbagai situasi. Adapun mempelajari budaya bekerja Jepang harus dipersiapkan oleh orang Indonesia yang akan bekerja di perusahaan Jepang agar dapat mudah beradaptasi dan kegiatan pekerjaan pun menjadi lancar.

\section{KESIMPULAN}

Berdasarkan hasil penelitian di atas, dapat disimpulkan bahwa penerapan etiket bisnis Jepang yang dilakukan oleh pekerja lokal adalah sebagai berikut.

Pertama, intensitas penerapan tinggi dalam hal etiket aisatsu (salam). Pekerja lokal sudah biasa menggunakan salam dalam lingkungan pekerjaan. Kemudian, dalam berinteraksi dengan ekspatriat Jepang, mayoritas pekerja lokal menggunakan salam dalam bahasa Jepang.

Kedua, etiket ojigi (membungkuk) cenderung diterapkan oleh pekerja lokal ketika bertemu, meminta maaf, berterimakasih, dan meminta tolong kepada ekspatriat Jepang.

Ketiga, intensitas penerapan rendah dalam bertukar kartu nama dengan ekspatriat Jepang, hal ini dapat disebabkan oleh jenis pekerjaan yang dilakukan oleh pekerja lokal di tempat kerja tidak selalu bersinggungan dengan ekspatriat Jepang.

Keempat, dalam berbagai macam situasi yang menggambarkan etiket menelepon, pekerja lokal telah menerapkan etiket tersebut dengan baik. Hal ini mencerminkan, adanya persamaan etiket orang Indonesia dan orang Jepang dalam hal menelepon.

\section{DAFTAR PUSTAKA}

Chang, W. (2016). Etika dan Etiket Bisnis. Yogyakarta : Kanisius

Flexbs. (n.d). Bijinesu no Kibon Manaa. http://flexbs.com/images/content/01.pdf Diakses 28 Februari 2021

Investor Daily Indonesia. (2018). 1500 Perusabaan Jepang Beroperasi di Indoneisa. https://investor.id/archive/1500-perusahaan-jepang-beroperasi-di-Indonesia/ diakses 28 Februari 2021

Jetro. (2020). Survei Kondisi Bisnis Perusahaan Jepang di Asia dan Oseania Tabun 2019 Mengenai Kondisi Perusahaan Jepang di Indonesia. Jakarta : Japan External Trade Organization

Shibata, H., Takahashi, J., \& Gyoba, J. (2015). Subjective Impressions of Bowing Actions and Their Appropriateness in Specific Social Contexts. The Japanese Journal of Psychology. 85(6): 571 578

Shinmura, I. (2012). Kojien Dairokuhan. Tokyo : Iwanama Shoten.

Tamura, G. (2013). Kiso Kara Manabu Bijinesu Manaa Koura. Yokohama : Keiri Senmon Gakkou 